\title{
Investigation of Current Methods to Identify Helicopter Gear Health
}

\author{
Paula J. Dempsey ${ }^{*}$ \\ NASA Glenn Research Center \\ Cleveland, Ohio 44135 \\ David G. Lewicki ${ }^{\dagger}$ \\ U.S. Army Research Laboratory \\ Cleveland, Ohio 44135 \\ Dy D. Le \\ Federal Aviation Administration \\ William J. Hughes Technical Center \\ Atlantic City International Airport, New Jersey 08405
}

\begin{abstract}
This paper provides an overview of current vibration methods used to identify the health of helicopter transmission gears. The gears are critical to the transmission system that provides propulsion, lift and maneuvering of the helicopter. This paper reviews techniques used to process vibration data to calculate conditions indicators (CI's), guidelines used by the government aviation authorities in developing and certifying the Health and Usage Monitoring System (HUMS), condition and health indicators used in commercial HUMS, and different methods used to set thresholds to detect damage. Initial assessment of a method to set thresholds for vibration based condition indicators applied to flight and test rig data by evaluating differences in distributions between comparable transmissions are also discussed. Gear condition indicator FM4 values are compared on an OH58 helicopter during 14 maneuvers and an OH58 transmission test stand during crack propagation tests. Preliminary results show the distributions between healthy helicopter and rig data are comparable and distributions between healthy and damaged gears show significant differences.
\end{abstract}

\section{Introduction}

Helicopter transmission integrity is important to helicopter safety because helicopters depend on the power train for propulsion, lift, and flight maneuvering. A study of 1168 helicopter accidents from 1990 to 1996 found that after human-factors related causes of accidents, the next most frequent causes of accidents were due to various system and structural failures. ${ }^{1}$ In 1999, of the world total of 192 turbine helicopter accidents, 28 were directly due to mechanical failures with the most common in the drive train of the propulsion system. ${ }^{2}$ Liu and Pines ${ }^{3}$ continued the study performed by NASA from 1998 to 2004. Their study showed the number of accidents caused by vehicle factors compared to the total number of accidents have been reduced by more than one half from earlier accident data. Pilot error continues to be the major cause of all rotorcraft accidents and failure or malfunction of the propulsion system remains the primary reason for vehicle factor related accidents. In order to reduce helicopter accidents, the original study ${ }^{1}$ recommended the design of HUMS capable of predicting impending equipment failure for on-condition maintenance, and more advanced systems capable of warning pilots of imminent equipment failure. In order to make these predictions, the system must provide health monitoring of the transmission components and must also demonstrate a high level of reliability to minimize false alarms.

Figure 1 shows the potential economic and safety benefits of diagnostics and predictive maintenance of critical mechanical systems. If usage is more severe than design life of a component, health monitoring will provide a safety benefit. If usage is less severe, the service life of critical components may be extended. Although commercially available HUMS provide safety benefits when installed on rotorcraft, the damage detection rate of today's helicopter

\footnotetext{
*Aerospace Research Engineer, NASA Glenn Research Center, 21000 Brook Park Road, and nonmember.

${ }^{\dagger}$ Senior Aerospace Engineer, NASA Glenn Research Center, 21000 Brook Park Road, and nonmember.

${ }^{*}$ Rotorcraft Program Manager, Federal Aviation Administration Air Traffic Organization, William J. Hughes Technical Center, and nonmember.
} 


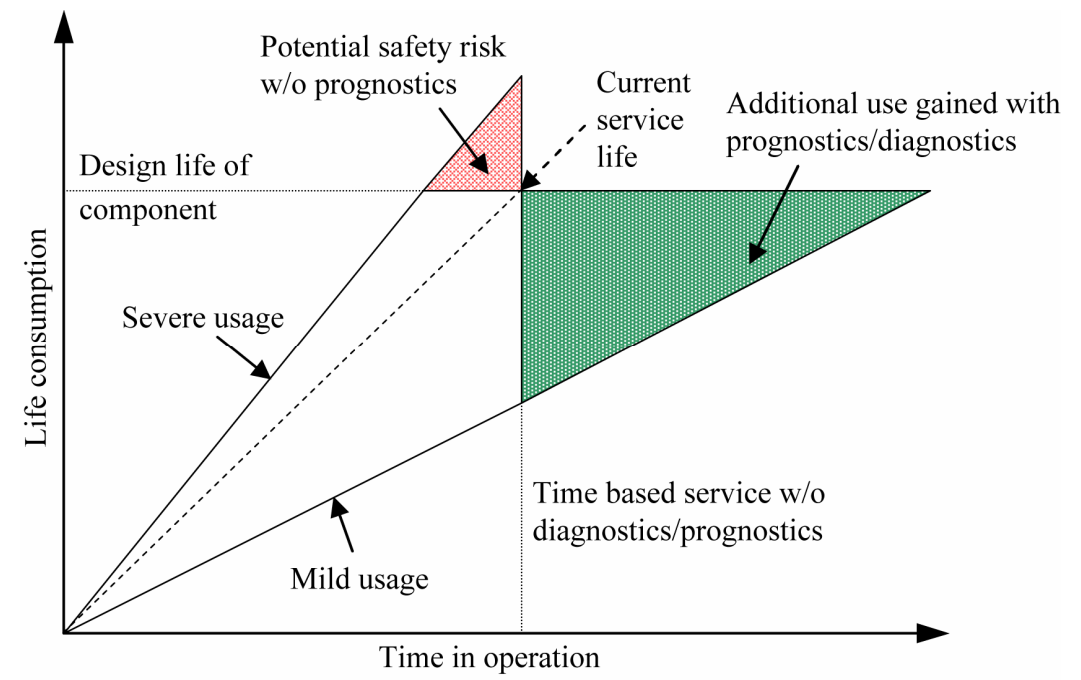

Figure 1.-Economic and Safety Benefits of Diagnostics and Prognostics. ${ }^{40}$

health monitoring systems through vibration analysis can be improved. HUMS experience documented by the United Kingdom Civil Aviation Authority (CAA) in 1997, and informally updated in 2002, shows a success rate of 70 percent in detecting defects. ${ }^{4}$

The following challenges still need to be addressed to achieve the safety and economic potential of an integrated health monitoring system: ${ }^{5}$

- Limited helicopter vibration fault data.

- Diagnostic tool operational constraints are undefined.

- Systems complex-Experts required for data analysis.

- Decision-making on system health difficult.

- Standard thresholds for types/levels of damage are not clearly defined.

- Performance assessment methods have not been developed.

- Tradeoffs between fault detection and false alarms.

These challenges must be addressed at the subsystem level prior to development of an overall integrated helicopter health monitoring system.

This paper will provide an overview of current vibration based methods used to identify gear component damage in commercial HUMS. The standard techniques used to process vibration data and calculate vibration algorithms to detect gear damage will be discussed first. Then a brief overview of the guidelines provided by the FAA and CAA in developing and certifying HUMS will be provided. Next, the vibration condition and health indicators used in commercial HUMS will be discussed including results of a survey sent to several manufacturers. Then, different methods used to set thresholds to detect damage will be outlined. Initial assessment of a method to set thresholds applied to flight and test rig data will be discussed.

\section{Gear Diagnostic Algorithms}

Numerous diagnostic techniques have been developed from vibration data to detect damage and abnormal conditions of the dynamic mechanical components in rotorcraft propulsion systems. A majority of the technology developed focused on the gear health. Using vibration data collected from gearbox accelerometers, algorithms are developed to detect when gear damage has occurred. Other areas addressed include bearings and driveshafts of the main transmission system. This work will focus on vibration algorithms available in commercial HUMS used to detect gear damage.

Gear damage produces changes in the vibration signatures measured by accelerometers installed on the gearbox. Over the past 25 years, numerous vibration-based algorithms for mechanical component damage detection in transmissions have been developed. The traditional methods of vibration based gear feature detection and extraction methods in rotating equipment, discussed in detail by, ${ }^{6}$ are typically based on some statistical measurement of vibration energy. The primary differences are based on which of the characteristic frequencies are included, 
excluded, or used as a reference. Figure 2 is a block diagram of the steps required to calculate FM4 (Figure of Merit 4), a common vibration algorithm used in commercial HUMS.

Referring to figure 2, once the vibration time series data is collected from the accelerometers, the first step to define the gear vibration algorithm is to calculate the time synchronous average (TSA) of the data. Gears produce vibration signals synchronous with speed. Noise in the vibration signal is reduced using time synchronous averaging. Synchronous averaging refers to techniques for extracting periodic waveforms from additive noise by averaging vibration signals over several revolutions of the shaft. ${ }^{7}$ The typical signal time synchronous average is obtained by taking the average of the signal in the time domain. Using the once per revolution signal, the vibration signal is interpolated into a fixed number of points per shaft revolution. The number of interpolated points are typically a power of two $(512,1024$, etc.). This makes implementing frequency domain signal processing techniques significantly easier. The desired signal, which is synchronous with the shaft speed, will intensify relative to the nonperiodic signals. It should be noted that sample rates of the vibration time series data determines the number of averages that can be obtained for the time synchronous averaging. The vibration data is also filtered with a low band pass anti-aliasing filter prior to data acquisition to prevent aliasing caused when the sample rate is less than twice the bandwidth of the input signal.

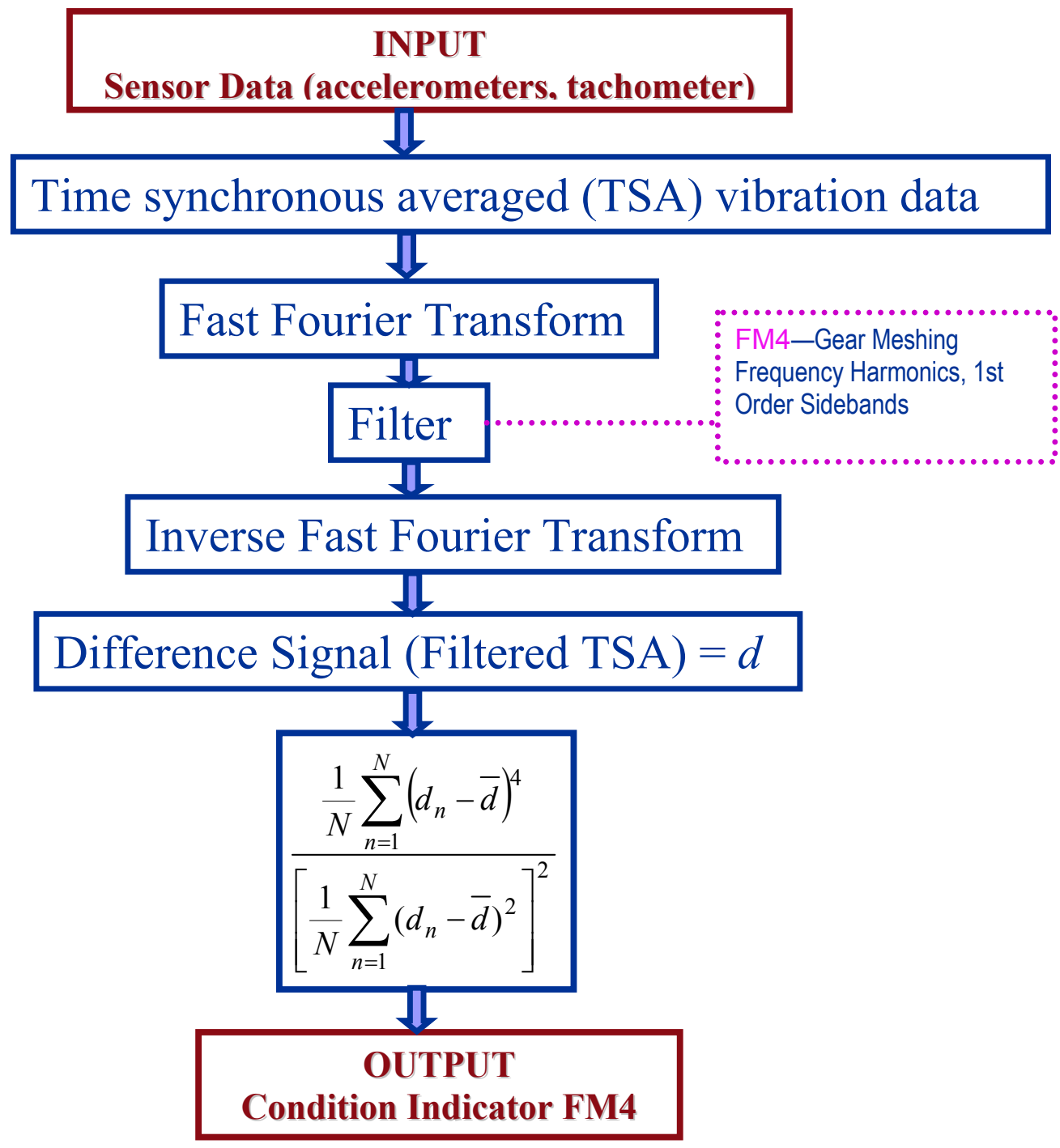

Figure 2.-Flowchart for calculating standard vibration algorithms FM4. 
After the accelerometer data is sampled and time synchronous averaged to shaft speed, the time domain data is converted to frequency domain data using a fast Fourier transform. The amount of filtering is defined by the algorithm. FM4 (Figure of Merit 4) was developed to detect changes in the vibration pattern due to damage (pitting, small, cracks) on a limited number of teeth. ${ }^{7}$ For FM4, gear meshing frequency, harmonics, and 1st order sidebands are removed from the original signal. This signal is converted back to the time domain. Then a statistical parameter, the fourth normalized statistical moment (normalized kurtosis) of the difference signal, is calculated from this data, where $d$ is the difference signal, $\bar{d}$ is the mean value of the difference signal and $N$ is the total number of interpolated points per reading. The kurtosis of a normal distribution equals 3 . In theory, for healthy gears, the difference signal would be Gaussian noise, resulting in a value of 3 . When one or two teeth develop a defect (such as a crack or pitting) a peak or series of peaks appears in the difference signal and FM4 reacts by increasing above this nominal value of 3 .

\section{FAA and CAA HUMS Guidance}

In 1999, the FAA published Advisory Circular (AC) 29-2C, Section MG-15, hereafter referred as the HUMS AC. ${ }^{8}$ The HUMS AC provides guidance for achieving airworthiness approval for installation, credit validation, and instructions for continued airworthiness (ICA) for a full range of HUMS application. Installation includes all the equipment needed for the end-to-end application that is associated with acquiring, storing, processing, and displaying the HUMS application data, including airborne and ground-based equipment. Credit validation includes evidence of effectiveness for the developed algorithms, acceptance limits, trend setting data, tests, etc., and the demonstration methods employed. A plan is needed to ensure continued airworthiness of those parts that could change with time or usage and includes the methods used to ensure continued airworthiness. The AC establishes an acceptable means, but not the only means of certifying a rotorcraft HUMS. Certification of HUMS addresses the complete system, including quality assurance of data produced from the airborne modules of the HUMS, and the potential subsequent intervening actions resulting from the ground processing of the airborne data.

Setting reliable thresholds is related to the credit validation phase of HUMS certification by providing evidence of condition indicators effectiveness through reliable threshold limits. In order to obtain maintenance credits, alert limits and intervention actions must be defined based on direct evidence of the failure mechanism. If seeded fault tests are used to measure the performance of condition indicators, the tests must be verified as representative of flight data.

In 1999, the CAA also came out with Civil Aviation Publication (CAP) 693 that provides operators with guidelines for installation and use of health monitoring systems. The CAP described the level of monitoring required and provided advice on ensuring that the monitoring was effective and reliable. The section on threshold setting and adjustment states that thresholds must be defined in the form of absolute signal values, number of standard deviations above the mean fleet value, or other means. Trends for indicators that require trend monitoring must also be defined. In the threshold changes section it states that changing the limits requires an understanding of the relationship between the algorithm values and the increase in the severity of the fault detected based on the history of the component. ${ }^{9}$

In 2006, the Civil Aviation Authority came out with CAP 753, to provide additional guidance for Operators using vibration health monitoring (VHM) in helicopter rotor and drive systems. In this document they define VHM as, "the monitoring of vibration data and characteristics that can provide advance information relating to the development of incipient failures in the engine(s) rotor drive systems". ${ }^{10}$ Gear tooth indicators that can detect gear tooth damage and cracks are identified as required indicators. The signal acquisition and processing section of this document discusses the importance of sampling rate and signal averaging for VHM. Thresholds, discussed in the alert generation and management section of this document, may be set at absolute vibration levels based on fleet experience or learned for an individual helicopter. Thresholds can be set as alerts, to indicate inspections, or as alarm to indicate that flights should be avoided until maintenance has been performed. The thresholds are dependent on different flight regimes. The VHM system is required to detect 70 percent of the failure modes it is designed to monitor. Data must be capable of being downloaded within a 10 hour time period. System performance should be evaluated for alert/false alarm rates and success/failure rates to detect component damage.

\section{Commercial HUMS Vibration Algorithms}

An article in Rotor \& Wing magazine provided a good overview of commercial HUMS. ${ }^{11}$ HUMS consist of a main computer for data processing and acquisition of in-flight data from accelerometers and tachometers installed on critical aircraft components. If the aircraft is equipped with a flight data recorder, the system may also collect data from 
the recorder. Components that are monitored include the main and tail rotors, their gear boxes and drive trains. Vibration data is typically downloaded by a mechanic post flight. The main function is to collect data to identify normal and abnormal changes in vibration levels on an aircraft's critical components. Typically the boundaries of "normal" performance are identified during flight testing. All commercial HUMS use vibration algorithms for gears calculated using the steps discussed in the gear vibration algorithms section of this paper. Threshold configurations can be different for each system. Techniques utilized by three HUMS manufacturers are reviewed in the following paragraphs.

The Goodrich Integrated Mechanical Diagnostics Health and Usage Management Systems (IMD-HUMS) mechanical diagnostics capabilities include drive train vibration information analyzed in-flight to determine drive train health. A number of condition indicators are calculated from vibration data to characterize component health. The IMD-HUMS has limit exceedance capabilities on drive train vibration levels for condition indicators (CI) and health indicators (HI). ${ }^{12}$ Condition Indicators (CI) refer to gear vibration algorithm used to reflect the health of the gear, such as FM4. Goodrich calculates several CI's for a component. The U.S. Army and the Goodrich Corporation have undertaken a battalion-level demonstration of the Goodrich Integrated Mechanical Diagnostics Health and Usage Monitoring System (IMD HUMS). A paper by Wright ${ }^{13}$ provides an overview of benefits utilizing the automatic acquisition of drive train component CI's. Significant detections have been made to date of problems on the helicopter. Comparisons between aircraft are being used to verify and validate some indicators. However, final health limits and thresholds are not defined for every component.

In 1993, the U.S. Navy provided the groundwork for the current Goodrich IMD-HUMS through work on an H-60 Helicopter Integrated Diagnostic System (HIDS). ${ }^{12}$ Flight and ground tests were performed to develop and evaluate diagnostic algorithms for the HIDS. Additional work was performed installing the IMD-HUMS on the H-53 platform. These programs demonstrate the capabilities of the IMD HUMS as a tool for rotorcraft health management and diagnostics. Navy researchers have also performed preliminary research applying multivariate statistical process control techniques to produce a single indicator on the state of a system. This technique was applied to drive system seeded fault tests with promising results. ${ }^{14}$

Intelligent Automation Corporation developed a HUMS system with the U.S. Army under the Vibration Management Enhancement Program (VMEP) to monitor the health of drive system dynamic components. The system consists of an on-board computer to collect and processes vibration information in flight, ground based software for displaying information to maintenance personnel, and web-based infrastructure tools for data archiving and analysis. ${ }^{15}$ Data acquisition can be triggered at a specific time or during a specific flight regime. FM4 is one of several algorithms used as a condition indicator to threshold or trend for fault diagnostics. Keller ${ }^{16}$ provides and overview of the drive train faults, 4 bearings and 1 shaft, discovered to date in over 70 aircraft equipped with the VMEP system. A database of drive train condition indicators has been developed from the data collected to date.

Smiths Aerospace developed the GenHUMS (Generic HUMS). GenHUMS has been in operational service in the UK Chinook fleet since 2000. The GenHUMS also includes powertrain and gearbox diagnostics in their health monitoring system. Smiths Aerospace and Bristow Helicopters are also developing a HUMS anomaly detection system under support from the CAA because HUMS data has shown that not all defect related trends or changes in HUMS data are detected with current threshold setting methods. They provided an example of large crack in a bevel pinion of a main gearbox that did not generate alerts from the vibration indicators. The objective of their work is to develop a method to identify abnormal behavior by comparing it to a data set of "normal" behavior. ${ }^{17}$

Preliminary work was done by Boeing to investigate a method to evaluate diagnostic algorithms and define criteria for threshold settings and compiled into a report, "Monitor the Monitors, RITA Metrics Document." A conceptual design of a Graphical User Interface was developed for a tool, but implementation procedures were not defined and the tool was never validated due to the limited amount of transmission seeded fault data available for assessment of vibration algorithm performance. ${ }^{18}$

\section{HUMS Survey Results}

A survey was sent to the 3 HUMS manufacturers (Goodrich, Intelligent Automation Corporation, Smiths Aerospace) to compare the methods used for identifying drive train component damage. The survey contained the following questions related to their systems:

- Number/locations of sensors (accelerometers, $1 \mathrm{X} / \mathrm{rev}$ )

- Time synchronous averaging techniques

- Vibration algorithms used for gears and bearings

- Data collection information (frequency, amount, type) 
- Regime/maneuver recognition

- Operational constraints

- Decision making tools using condition indicators (CI's)

- System performance and reliability metrics

All three manufactures provided valuable information on the capabilities of their HUMS. ${ }^{19-21}$ Results of the survey indicated commercial HUMS shared many similar traits. The number and location of sensors and time synchronous averaging techniques were comparable. The CI's for drive train components were similar. Data collection rates and amount/type of data saved is user selectable. There are some operational constraints regarding data collection during stable regimes with minimal transitions. Data collection can be automatic based on specified conditions. Smiths has found that data collected in normal cruise conditions at 60 to 70 percent torque provides the best flight regime for monitoring gear CI's. Some systems monitor torque for regime/maneuver recognition but the threshold adjustment based on torque varies. Some systems access several parameters in addition to speed and torque such as airspeed, altitude, rate of descent that can be correlated with CI's. Decision making tools using vibration algorithms or condition indicators (CI's) integrated into health indicators (HI's) are under development by several manufacturers. HI's provide decision making tools for the end user on the status of system health. Overall, CI and HI performance and reliability is very difficult to evaluate due to limited failure data available to assess performance. Published CI and $\mathrm{HI}$ threshold setting methods currently under development by the three manufacturers will be discussed in the next two paragraphs.

Intelligent Automation Corporation created a tool for developing a standard dataset of CI's. ${ }^{22} \mathrm{New}$ CI data is compared to the standard dataset to determine if the new data fits within the standard data set as normal or a specific fault class. Then data is accepted or rejected based on a rejection threshold. If the data is accepted it can be added to the standard data set after review by qualified personnel.

Goodrich is developing proprietary statistical procedures to define sets of threshold for each aircraft type and component by modeling the effect of variance across aircraft and torque on transmission components. ${ }^{23}$ Thresholds use a "healthy" data set that spans a subset of the fleet and the operating conditions. Variance for different helicopters and torque levels is estimated using a least square estimator, then corrected for small sample by using Student's t-distribution to test for statistical significance between two sample means. Their system is also capable of integrating several CI's into one health indicator (HI) that can be used to identify when a component requires additional analysis or a component is faulted. ${ }^{23-25}$ Fusing CI's sensitive to a specific failure can minimize the amount of information used by end user to make a decision on system health.

Smiths is currently developing and fielding health indicators (HI) for the end user to easily interpret the system health. ${ }^{21}$ In the past, simple thresholds were identified for condition indicators. More work was performed on statistical analysis of CI data distributions. Rule based systems have also been used. Smiths has found that the mentioned threshold setting tools may identify classic faults, but cannot identify novel faults that can occur 50 percent of the time. Using Artificial Intelligence (AI) reasoners, Bayesian statistics, data mining, clustering and failure modes and effects analysis models, they have been successful identifying novel, unanticipated faults such as sensor failures. They have rerun 6 years of archived data using their anomaly detector HI with promising results. This anomaly detection technique will not replace the current HUMS threshold setting methods. Rather, it will provide additional capabilities to the current HUMS threshold setting methods.

\section{Environmental Effects on Vibration Methods}

The usage monitoring piece of the HUMS consists of measuring torque, engine operating hours and flight hours to track usage of aircraft. Flight regimes and environmental operating conditions can also be included. The sensitivity of the CI'S to environmental effects in varying flight regimes must be taken into consideration when setting thresholds. Understanding the significant effects of operating conditions on CI's is important to defining reliable thresholds. Preliminary work has been performed evaluating gear CI's under varying load, speed and flight conditions, but more work is required. ${ }^{26,27}$ Limited work has been performed verifying that thresholds defined in test rigs can classify helicopter transmission health. This is due to limited availability of flight fault data to verify damage detection sensitivity demonstrated in test rigs can be maintained in flight in different flight regimes. ${ }^{28,29}$

\section{Setting Thresholds}

The goal for setting thresholds to indicate drive train health is to provide the minimum number of false alarms while maintaining sensitivity to gear damage. As mentioned in the previous sections, HUMS manufacturers use several methods to define thresholds. One of the biggest challenges when defining the threshold or limit of a 


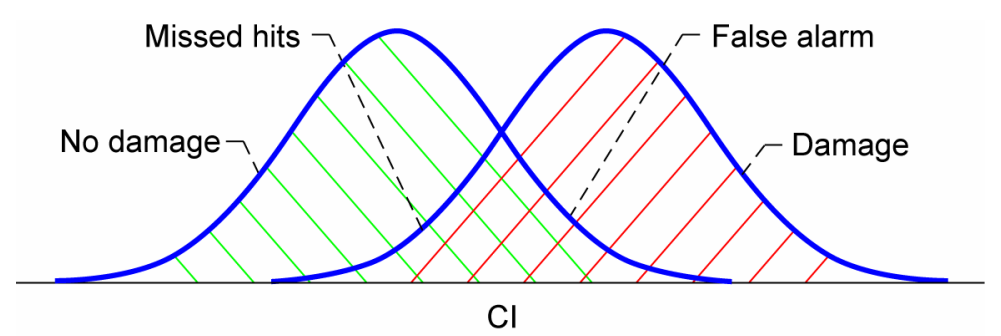

Figure 3.-Probability of no damage/false alarms and damage detected/missed hits.

diagnostic tool is the tradeoff between the sensitivity of the limit to indicate damage and the number of false alarms. If a limit is decreased, damage may be detected, but more false alarms may result. If a limit is increased, false alarms may decrease, but the algorithms will be less sensitive to damage. Figure 3 illustrates 2 distributions used to represent a no damage response and a damage response of a condition indicator.

Based on the $\mathrm{CI}$ value and the health of the component, table 1 provides the results of the decisions made on a given CI. Interpreting the overlapping region illustrated in figure 3 is the challenge to setting reliable thresholds based on the CI.

\section{A. Hypothesis Tests}

Figure 3 and table 1 are related to hypothesis tests used in statistical analysis. A hypothesis test is defined by testing the value of a population parameter, the null hypothesis, $\mathrm{H}_{0}$. The alternative hypothesis, $\mathrm{H}_{1}$, is the statement that must be true if the null hypothesis is false.

TABLE 1.-RESULTS OF DAMAGE/NO DAMAGE DECISIONS

\begin{tabular}{|l|l|l|l|}
\hline \multicolumn{2}{|c|}{} & \multicolumn{2}{c|}{ Health of component } \\
\cline { 3 - 4 } Decision & Indicate no damage & Correct decision & Missed hit \\
\cline { 2 - 4 } & Indicate damage & False alarm & Correct decision \\
\hline
\end{tabular}

Table 2 represents the hypothesis parameters for the decisions listed in table 1 . The hypothesis is defined to test that the mean of the $\mathrm{CI}$ from the undamaged gear looks significantly different than the mean of the $\mathrm{CI}$ of the damaged gear. A test statistic is used to make the decision to reject the null hypothesis based on the probability of acceptable error. Referring to table 2, if the null hypothesis is rejected when it is true, this results in Type I error (false positive) If you fail to reject the null hypothesis when it is false, this results in Type II error (false negative). An earlier analysis of flight data found the mean could vary 3 standard deviations within a healthy set of CI data. ${ }^{29}$ The variance within the data must be considered when defining a test statistic to set thresholds to minimize the occurrence of false alarms.

TABLE 2.-HYPOTHESIS OF DAMAGE/NO DAMAGE DECISIONS

\begin{tabular}{|c|l|l|l|}
\hline \multicolumn{2}{|c|}{} & \multicolumn{2}{|c|}{ True state of system } \\
\cline { 2 - 4 } \multicolumn{2}{|c|}{} & $\begin{array}{l}\mathrm{H}_{\mathrm{o}} \text { is true } \\
\mathrm{H}_{\mathrm{o}}: \mu \leq \mathrm{CI} \\
\text { Gear is healthy }\end{array}$ & $\begin{array}{l}\mathrm{H}_{\mathrm{o}} \text { is false } \\
\mathrm{H}_{1}: \mu>\mathrm{CI} \\
\text { Gear is damaged }\end{array}$ \\
\hline \multirow{2}{*}{ Decision } & Reject $\mathrm{H}_{\mathrm{o}}$ & $\begin{array}{l}\text { False alarm } \\
\text { (Type I error) }\end{array}$ & Correct decision \\
\cline { 2 - 4 } & Fail to reject $\mathrm{H}_{\mathrm{o}}$ & $\begin{array}{l}\text { Correct decision } \\
\text { Healthy component }\end{array}$ & $\begin{array}{l}\text { Missed hit } \\
\text { (Type II error) }\end{array}$ \\
\hline
\end{tabular}

\section{B. Bayesian Statistics}

Bayesian inference is another statistical analysis technique that can be used for setting thresholds to make a decision on component health. Bayesian inference updates the likelihood of a hypothesis (probability a hypothesis is true) given a previous likelihood estimate and additional evidence (observations). Bayesian inference can be used to determine the probability that a diagnosis of gear damage is correct given a priori information. An example of an equation for Bayesian inference to set damage detection thresholds is: 


$$
P\left(f_{i} / O\right)=\frac{P\left(O / f_{i}\right) \cdot P\left(f_{i}\right)}{\sum_{i} P\left(O / f_{i}\right) \cdot P\left(f_{i}\right)}
$$

where $P\left(f_{i} / O\right)$ equals the probability of fault $\left(f_{i}\right)$ given diagnostic output $(O), P\left(O / f_{i}\right)$ equals the probability that a diagnostic output $(O)$ is observed with fault $\left(f_{i}\right)$, and $P\left(f_{i}\right)$ is the a priori probability of $\left(f_{i}\right)$ occurring. ${ }^{30,31}$

Due to limited fault data, it is challenging to apply Bayesian inference to identifying component health. Bayesian inference requires knowledge about the diagnostic system to generate the $a$ priori distributions and $a$ priori probabilities of the hypotheses. The complexity of the data due to multiple hypotheses (several vibration algorithms and damage levels) and multiple conditional dependent events (maneuvers, time dependent data) also make it difficult to define levels of probability for each scenario. Bayesian statistics may be useful when applied to fault classification, where a large amount of fault data is acquired on different types of faults. ${ }^{32}$

\section{Fuzzy Logic}

Fuzzy logic has been successfully used to set thresholds to identify gear damage and to make a decision on the health of the system. ${ }^{28,33}$ Earlier studies found fuzzy logic, as compared to production rules and neural networks, the most robust when monitoring transitional failure data on a gearbox. ${ }^{34}$ Another study comparing automated reasoning techniques for condition-based maintenance found fuzzy logic more flexible than standard logic by making allowances for unanticipated behavior. ${ }^{35}$ Fuzzy logic applies fuzzy set theory to data, where fuzzy set theory is a theory of classes with unsharp boundaries. The data belongs in a fuzzy set based on its degree of membership. ${ }^{36}$

Fuzzy logic starts with a fuzzy set, extending boolean set theory to a continuous valued logic via the concept of membership functions valued between 0 and 1 . A membership function is a curve that defines how each point in the input space is mapped to a membership value or degree of membership between 0 and 1 . The only condition a membership function must satisfy is that it is a continuous function that varies between 0 and 1 . Once membership functions are defined for a fuzzy set, fuzzy rules must be defined. Fuzzy rules are defined by experts in the field. Experts express their field knowledge in rules with an IF-THEN format. An example of a fuzzy if-then rule is, "if $x$ is A then y is B." The final step is to convert the fuzzy membership information and rules into a crisp output using defuzzification methods.

Figure 4 is an example of using fuzzy logic to define health indicators from gear condition indicators. Gear condition indicators are calculated from sensor data. Membership functions are then developed for the CI's. Defining membership functions that accurately reflect the CI data is the challenge when using fuzzy logic to set thresholds. In this example, trapezoidal shaped membership functions were used. A certain amount of overlap is required or no rules will fire for values in the gap between the membership functions. The x-axis of the membership function refers to the CI values and the y-axis refers to the degree of membership. DL refers to Damage Low (Gear O.K), DM refers to Damage Medium (Inspect Gear) and DH refers to Damage High (Shutdown System). The basic rules are defined based on the level of damage indicated by the CI and experience with the CI to detect specific faults in certain environmental conditions. Membership functions and rules can be added for additional CI's. The degree of membership for the output of the fuzzy model provides the status of gear health. For this example O.K indicates no gear damage, Inspect indicates initial pitting and Shutdown (due to damage) indicates destructive pitting. The output was defined to give the end user a simple function based on the state of the gear. A value of 0 to 0.33 indicates the gear is O.K., 0.33 to 0.66 indicates the gear should be inspected, and 0.66 to 1.0 indicates shutdown the system, the gear is damaged.

\section{Relative Frequency Plots}

Preliminary research was performed comparing probability distributions of CI's from a GRC spur gear component rig with and without gear damage and flight data from an $\mathrm{OH} 58$ helicopter under normal conditions. ${ }^{29}$ Histograms of the CI values were created for CI's measured in the test rig with and without damage and the CI's measured on a helicopter during several maneuvers. In order to compare the histograms with probability distributions, relative frequency plots were created scaling the histograms so that the area under the curve was equal to 1 . The relative frequency plots of the flight data were similar to the curves for NASA Glenn Research Center (GRC) component test rig data without gear damage. Distributions of the data also changed when damage occurred. This earlier work compared the data from helicopter flights to a simple test rig consisting of 2 meshing spur gears. In order to evaluate if differences in distributions are observed between comparable helicopter and test rig transmissions work has begun to evaluate the difference in distributions between flight data and a comparable transmission test stand. The next section will provide preliminary data to demonstrate this analysis. 


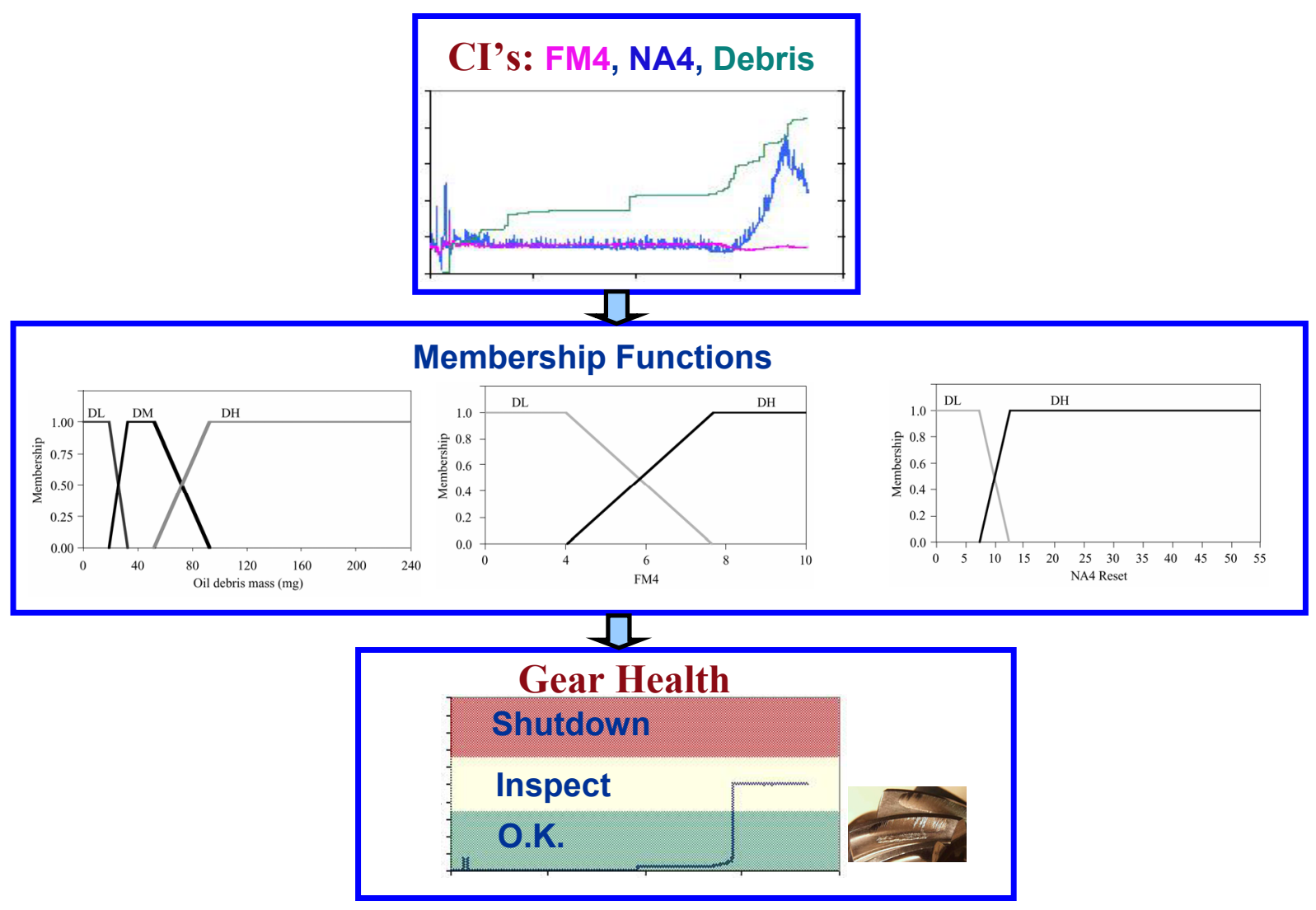

Figure 4.- Setting threshold from CI's using fuzzy logic.

\section{Setting CI Thresholds on OH58 Flight and Test Data}

Figure 5 illustrates the $\mathrm{OH} 58$ helicopter used to collected healthy $\mathrm{CI}$ data from accelerometers located on the transmission housing. ${ }^{37,38}$ For this analysis, only one accelerometer mounted horizontally and radial to the transmission will be discussed. No mechanical component damage was observed during flights. Data was collected from 14 different maneuvers each repeated 12 times. The maneuvers and average torque level during the maneuver are shown in table 3 . The pilot set-up the maneuver, then collected data for $34 \mathrm{sec}$. The component monitored for health was the main transmission 19 tooth input spiral bevel gear pinion. Vibration data was sampled at a rate of $50 \mathrm{kHz}$ with an anti-aliasing filter set at $18 \mathrm{kHz}$. For each 34-second maneuver, 48 time synchronous averages were calculated with 71 rotations in each average. In addition to vibration, torque and speed were also measured. The pinion was run at an average speed of $6278 \mathrm{rpm}$.

TABLE 3.-OH58 FLIGHT MANEUVERS

\begin{tabular}{|c|c|l|c|c|l|}
\hline Man & $\begin{array}{c}\text { Torque, } \\
\text { percent }\end{array}$ & \multicolumn{1}{|c|}{ Maneuver description } & Man & $\begin{array}{c}\text { Torque, } \\
\text { percent }\end{array}$ & \multicolumn{1}{|c|}{ Maneuver description } \\
\hline $\mathrm{A}$ & 55 & Level, forward $\sim 55$ percent torque & $\mathrm{H}$ & 74 & Hover, $\sim 10 \mathrm{ft}$ \\
\hline $\mathrm{B}$ & 80 & Level, forward $\sim 80$ percent torque & $\mathrm{I}$ & 74 & Hover $\sim 10 \mathrm{ft}$, turn left \\
\hline $\mathrm{C}$ & 58 & Level, sideways left & $\mathrm{J}$ & 73 & Hover $\sim 10 \mathrm{ft}$, turn right \\
\hline $\mathrm{D}$ & 58 & Level sideways right & $\mathrm{K}$ & 61 & $20^{\circ}$ bank left turn \\
\hline $\mathrm{E}$ & 55 & Climb, $\sim 55$ percent torque & $\mathrm{L}$ & 61 & $20^{\circ}$ bank right turn \\
\hline $\mathrm{F}$ & 15 & Descent, $\sim 15$ percent torque & $\mathrm{M}$ & 80 & Climb, $\sim 80$ percent torque \\
\hline $\mathrm{G}$ & 26 & Flat pitch on ground & $\mathrm{N}$ & 35 & Descent, 35 percent torque \\
\hline
\end{tabular}




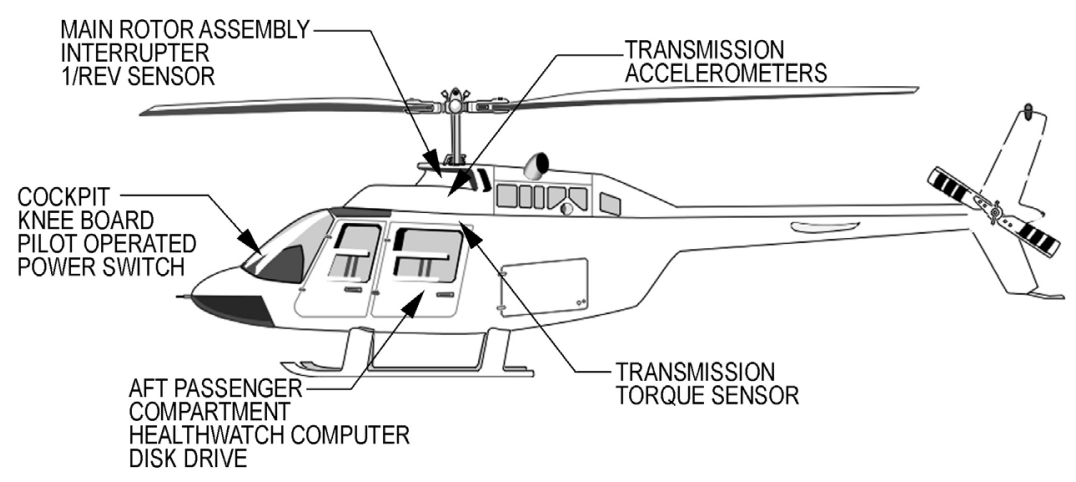

Figure 5.- $\mathrm{OH} 58$ helicopter.

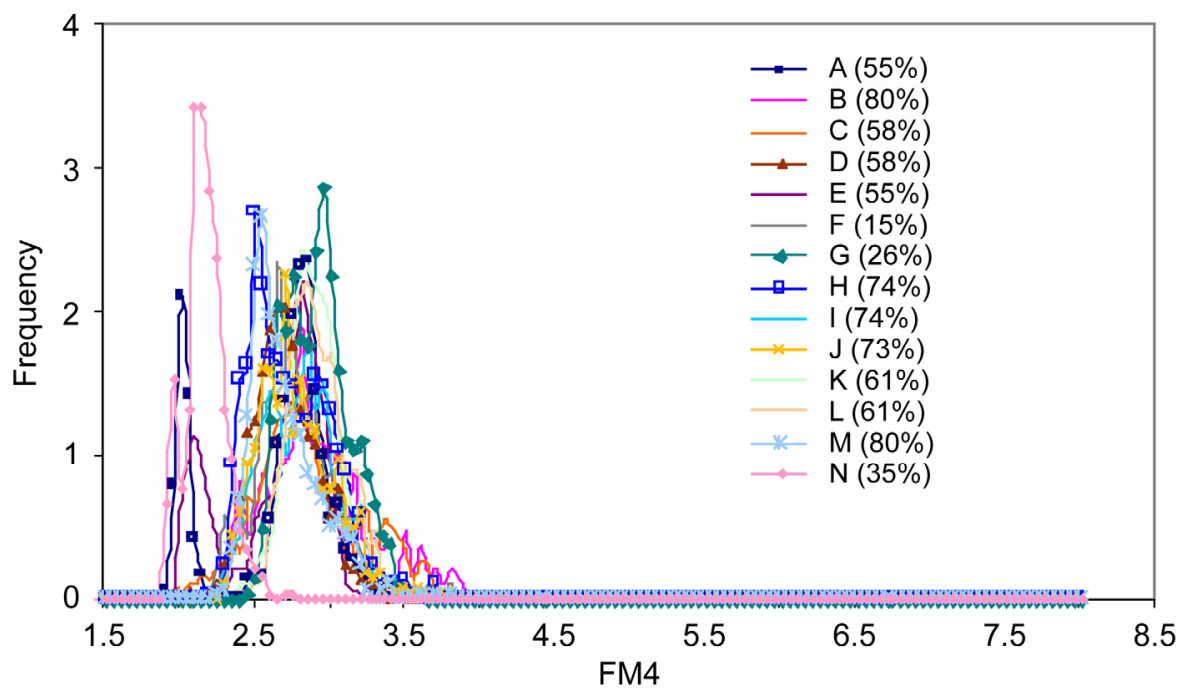

Figure 6.-OH58 Relative frequency plots of FM4 from NASA Ames OH58 flight tests.

Figure 6 shows the relative frequency plots for condition indicator FM4 from an accelerometer installed on the transmission housing during NASA Ames OH58 Flight Tests. For this data, histograms were created from the FM4 CI data for each maneuver with a bin width of 0.05 and a range of 1 to 8.5. The histogram data was then rescaled so the area under the curve (integral under the estimated distribution) is equal to 1 by dividing the counts by the bin size and total number of readings (counts/(readings*bin size). Although the minimum FM4 value for this accelerometer across all maneuvers was 1.87 and the maximum was 4.92, the majority of values fall within 2 and 3 . The distributions varied for each maneuver and the tails of the distributions shift to the right for higher torque levels, with the maximum FM4 value observed during maneuver B, 80 percent torque. The changes in the distribution for each maneuver shows that FM4 is effected by operational conditions.

Figure 7 illustrates the NASA GRC OH58 Helicopter Transmission Test Stand used to collect healthy and damaged $\mathrm{CI}$ data from accelerometers located on the transmission housing during a matrix of pinion crack propagation tests. ${ }^{39}$ The main transmission 19 tooth spiral bevel pinion gear, like the helicopter, was monitored for health. And, for this preliminary analysis, only one accelerometer mounted horizontally and radial to the transmission will be discussed. For these tests, a pinion tooth was notched and run several hours to facilitate a tooth fracture. In addition to vibration, torque and speed were also measured. The pinion was run at design speed of $6060 \mathrm{rpm}$ for all tests. Torque values ranged from 80 to 150 percent torques. Vibration data was sampled at a rate of $150 \mathrm{kHz}$ with an anti-aliasing filter set at $56 \mathrm{kHz}$. Data was sampled every $15 \mathrm{sec}$ for a $1.5 \mathrm{sec}$ duration. Time synchronous averages were calculated with 150 rotations in each average. 


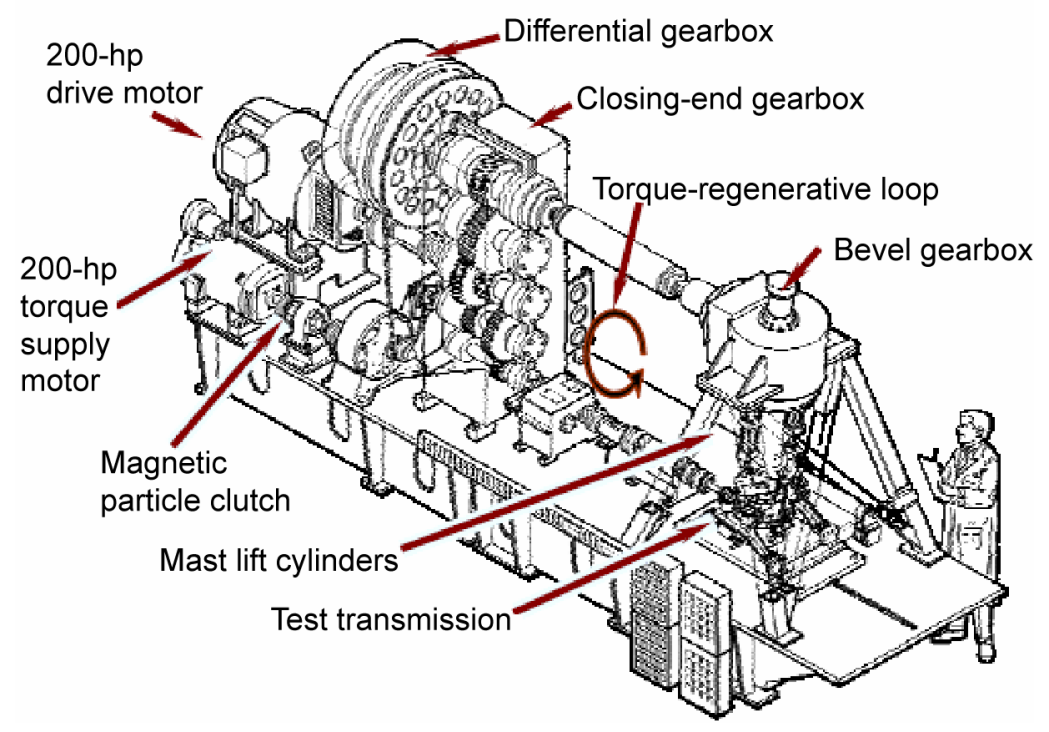

Figure 7.-NASA GRC OH58 Transmission test stand.

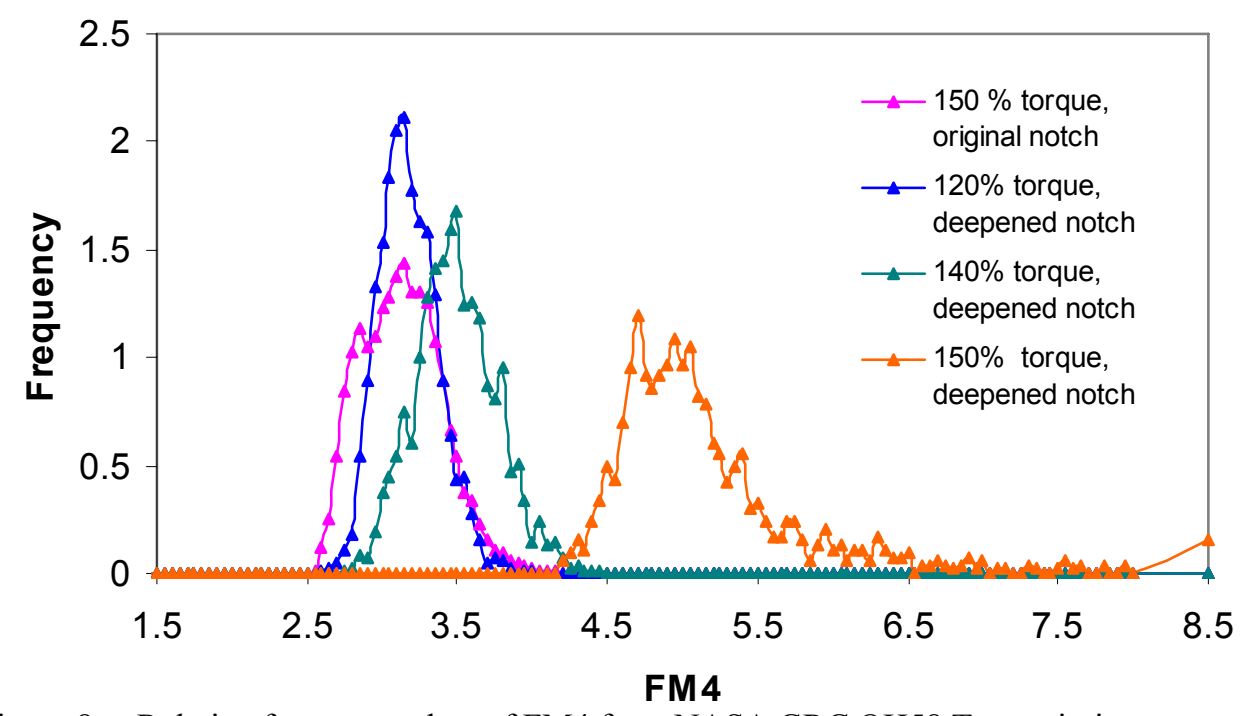

Figure 8.-Relative frequency plots of FM4 from NASA GRC OH58 Transmission test stand.

Figure 8 shows the relative frequency plots for condition indicator FM4 from an accelerometer installed on the transmission housing of the NASA GRC OH58 Test Stand. The pinion was run for $60.5 \mathrm{hr}$ at 150 percent torque with an initial notch fabricated on one tooth of the pinion. The notch was then deepened and the pinion ran an additional $5.5 \mathrm{hr}$ at 120 percent torque, $1.34 \mathrm{hr}$ at 140 percent torque, then $0.2 \mathrm{hr}$ at 150 percent torque and inspected several times within each torque cycle. A $60 \mathrm{X}$ microscope was used for visually inspecting the gear. It was known that no crack initiation occurred prior to the deepening of the notch. Crack initiation was also not observed after running at 140 percent torque. At completion of the test at 150 percent torque a tooth was found to be fractured. A picture of the tooth is shown in figure 9. For this data, histograms were created from the FM4 CI data at different torque levels $(120,140$, and 150 percent) with a bin width of 0.05 and a range of 1 to 8.5. The histogram data was also rescaled so the area under the curve is equal to 1 by dividing the counts by the bin size and total number of readings (counts/(readings*bin size). Note that the majority of values fall within 2.5 and 4.5 for the data sets with the healthy pinion. The distribution of the data shifts to 4.5 to 6.0 for the data set with the damaged pinion.

Additional work is required applying threshold setting methods discussed in the previous section to this data set and additional data from both the helicopter and the transmission test stand. 


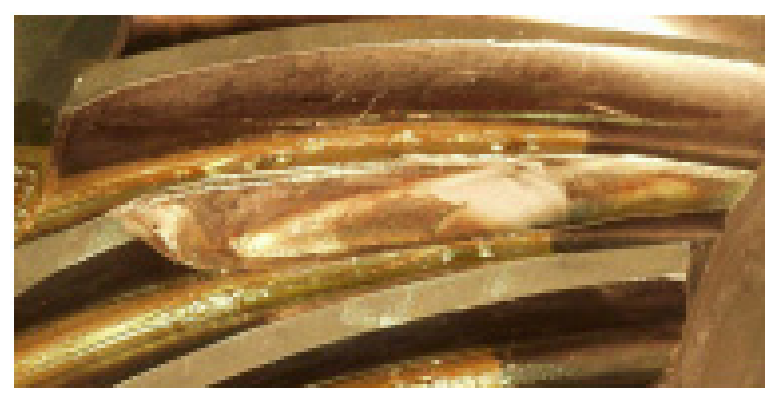

Figure 9.-Pinion cracked tooth at test completion.

\section{Summary}

This paper provided an overview of guidelines used by the FAA and CAA in developing and certifying HUMS, the techniques used to process vibration data to calculate conditions indicators (CI's), condition and health indicators used in commercial HUMS, and different methods used to set thresholds to detect damage. Initial assessment of a method to set thresholds applied to flight and test rig data was presented. Gear condition indicator FM4 distribution values on a healthy OH58 helicopter and a health OH58 transmission test rig were comparable. On the helicopter, distributions varied for each maneuver and the tails of the distributions shifted to the right (FM4 values increased) for higher torque levels. Distributions between healthy and damaged gears on the test rig showed significant differences, shifting to the right (FM4 values increased) with increased damage.

\section{Acknowledgements}

The authors would like to thank several experts in the HUMS field for providing valuable information via interviews and survey responses for this paper: Alan Duke and Eric Bechhoefer of Goodrich, Paul Grabill of Intelligent Automation Corporation, Andy Heather of Smiths Aerospace, Bill Hardman and Eric Carney of the Naval Air Warfare Center.

\section{References}

${ }^{1}$ Aviation Safety and Security Program, the Helicopter Accident Analysis Team, "Final Report of the Helicopter Accident Analysis Team," 1998.

${ }^{2}$ Learmount, D., Rotary Woes, Flight International, no. 4725, vol. 157, pp. 34-35, 2000.

${ }^{3}$ Liu, L. and Pines, D.J., "Analysis of U.S. Civil Rotorcraft Accidents Caused by Vehicle Failure/Malfunctions, 1998 to Present," presented at the American Helicopter Society 61st Annual Forum, Grapevine, TX, June 1-3, 2005.

${ }^{4}$ McColl, J., "Overview of Transmissions HUM Performance in UK North Sea Helicopter Operations. Rotorcraft Transmission Systems Health Monitoring Seminar," UK Civil Aviation Authority, Institution of Mechanical Engineers. London U.K., 18 Nov. 1977.

${ }^{5}$ Zakrajsek, J.J., Dempsey, P.J., Huff, E.M., Augustin, M., Safa-Bakhsh, R., Duke, A. Ephraim, P., Grabill, P. and Decker, H.J., "Rotorcraft Health Management Issues and Challenges," NASA/TM—2006-214022.

${ }^{6}$ Zakrajsek, J.J., "An Investigation of Gear Mesh Failure Prediction Techniques," NASA TM-102340, AVSCOM TM 89-C-005, November 1989.

${ }^{7}$ Stewart, R.M., "Some Useful Data Analysis Techniques for Gearbox Diagnostics," Machine Health Monitoring Group, Institute of Sound and Vibration Research, University of Southhampton, Report MHM/R/10/77, July 1977.

${ }^{8}$ Federal Aviation Authority, Advisory Circular, “Airworthiness Approval of Rotorcraft Health Usage Monitoring Systems (HUMS),” PS-ASW100-1999-00063, July 15, 1999.

${ }^{9}$ Civil Aviation Authority, CAP 693, "Acceptable Means of Compliance Helicopter Health Monitoring," CAA AAD 001-05-99, London, May 1999.

${ }^{10}$ Civil Aviation Authority, CAP 753, "Helicopter Vibration Health Monitoring (VHM) Guidance Material for Operators Utilizing VHM in Rotor and Rotor Drive Systems of Helicopters," June 2006.

${ }^{11}$ McKenna, J.T., An Eye on Operations. Rotor \& Wing. September 2005. 
${ }^{12}$ Hess, R., Duke, A. and Kogut, D., "The IMD HUMS as a Tool for Rotorcraft Health Management and Diagnostics," IEEE Aerospace Conference, 2001.

${ }^{13}$ Wright, J., "Emerging Results Using IMD-HUMS in a Black Hawk Assault Battalion,” AHS 61st Annual Forum, Grapevine, Texas, June 1-3, 2005.

${ }^{14}$ Mimnagh, M.L., Hardman, W. and Sheaffer, J., "Helicopter Drive System Diagnostics Through Multivariate Process Control," IEEE Aerospace Conference Proceedings, vol. 6 pp. 381-415, Big Sky, Montana, March 2000.

${ }^{15}$ Grabill, P. Brotherton, Berry, J. and Grant, L., "The US Army and National Guard Vibration Management Enhancement Program (VMEP): Data Analysis and Statistical Results," proceedings from the American Helicopter Society 58th Annual Forum, Montreal, Canada, June 11-13, 2002.

${ }^{16}$ Keller, J.A., Branhof, R.W., Dunaway, D., Grabill, P., "Examples of Condition Based Maintenance with the Vibration Management Enhancement Program," proceedings of the American Helicopter Society 61st Annual Forum, Grapevine, Texas, June 1-3, 2005.

${ }^{17}$ Larder, B., Callan, R., Salter, S., "Intelligent Management of HUMS Data: Development and Demonstration of a Vibration Health Monitoring Anomaly Detection System," presented at the American Helicopter Society 62nd Annual Forum, Phoenix, AZ, May 9-11, 2006.

${ }^{18}$ Safa-Bakhsh, R., Byington, C.S., Watson, M., and Kalgren, P., "Metrics Evaluation and Tool Development for Health and Usage Monitoring System Technology," presented at the American Helicopter Society 59th Annual Forum, Phoenix, Arizona, May 6-8, 2003.

${ }^{19}$ Duke, Alan and Eric Bechhoefer. Telephone interview on survey response. July 12, 2006.

${ }^{20}$ Grabill, Paul. Survey response via email. September 1, 2006.

${ }^{21}$ Heather, Andy. Telephone interview on survey response. October 19, 2006.

${ }^{22}$ Brotherton, T., Grabill, P., Friend, R., Sotomayer, B. and Berry, J., "A Testbed for Data Fusion for Helicopter Diagnostics and Prognostics," proceedings of the 2003 IEEE Aerospace Conference, Big Sky., Montana, March 2003.

${ }^{23}$ Bechhoefer, E., Bernhard, A., "Setting HUMS Condition Indicator Threshold by Modeling Aircraft and Torque Band Variance," proceedings of the 2004 IEEE Aerospace Conference, Big Sky, Montana, 2004a.

${ }^{24}$ Bechhoefer, E., Bernhard, A., "HUMS Optimal Weighting of Condition Indicators to Determine the Health of a Component," proceedings of the AHS 60th Forum, Baltimore, MD, 2004b.

${ }^{25}$ Bechhoefer, E., Mayhew, E., "Mechanical Diagnostics System Engineering in IMD-HUMS," proceedings of the 2006 IEEE Aerospace Conference, Big Sky, Montana, 2006.

${ }^{26}$ Dempsey, P.J. Zakrajsek, J.J., "Minimizing Load Effects on NA4 Gear Vibration Diagnostic Parameter," NASA/TM-2001-210671, February 2001.

${ }^{27}$ Mosher, Pryor, Huff., "Evaluation of Standard Gear Metrics in Helicopter Flight Operation," Proceedings of the 56th Meeting of the Society for Machinery Failure Prevention Technology, April 15-19, 2002, Virginia Beach, Virginia.

${ }^{28}$ Dempsey, P.J., Handschuh, R.F., and Afjeh, A.A., "Spiral Bevel Gear Damage Detection Using Decision Fusion," IEEE Aerospace and Electronics Systems Journal, Vol. 18, Issue 9, September, 2003.

${ }^{29}$ Dempsey, P.J., Mosher, M.M. and Huff, E.M, "Threshold Assessment of Gear Diagnostic Tools on Flight and Test Rig Data," NASA/TM-2003-212220, February 2003a.

${ }^{30}$ Kacprzynski, Gregory J.; Roemer, M.J.; Orsagh, R.F., “Assessment of Data and Knowledge Fusion Strategies for Diagnostics and Prognostics," Society for Machinery Failure Prevention Technology, H.C. Pusey, S.C. Pusey, and W.R. Hobbs, eds., Haymarket, VA, pp. 341-350, 2001.

${ }^{31}$ Hall, D.L., "Mathematical Techniques in Multisensor Data Fusion," Artech House, 1992.

${ }^{32}$ Erdley, J.D.; and Hall, D.L., "Improved Fault Detection Using Multisensor Data Fusion," Proceedings of the 52nd Meeting of the Society for Machinery Failure Prevention Technology, pp. 337-346, 1998.

${ }^{33}$ Dempsey, P.J. and Afjeh, A.A. "Integrating Oil Debris and Vibration Gear Damage Measurement Technologies Using Fuzzy Logic,” Journal of the American Helicopter Society, April 2004, Volume 49-Number 2.

${ }^{34}$ Hall, David L.; Garga, A.K.; and Stover, J., "Machinery Fault Classification: The Case for a Hybrid Fuzzy Logic Approach," Society for Machinery Failure Prevention Technology, H.C. Pusey, S.C. Pusey, and W.R. Hobbs, eds., Haymarket, VA, pp. 241-252, 1999.

${ }^{35}$ McGonigal, Daniel Lewis, “A Comparison of Automated Reasoning Techniques for Condition-Based Maintenance," M.A. Thesis, Pennsylvania State University, 1997.

${ }^{36}$ Zadeh, Lotfi A., "Outline of a New Approach to the Analysis of Complex Systems and Decision Processes," IEEE Trans. Syst. Man Cybern., vol. SMC-3, no. 1, pp. 28-44, 1973.

${ }^{37}$ Mosher, M., Huff, E.M. and Barszcz, E., "Analysis Of In-Flight Measurements From Helicopter Transmissions," presented at the American Helicopter Society 60th Annual Forum, Baltimore, Md, June 7-10, 2004. 
${ }^{38}$ Tumer, I.Y., Huff, E.M., "Using Triaxial Accelerometer Data For Vibration Monitoring Of Helicopter Gearboxes," Proceedings of DETC'01 2001 ASME Design Engineering Technical Conferences September 9-12, 2001, Pittsburgh, Pennsylvania.

${ }^{39}$ Decker, H.J. and Lewicki, D.G., "Spiral Bevel Pinion Crack Detection in a Helicopter Gearbox," proceedings of the American Helicopter 59th Annual Forum, Phoenix, Arizona, May 6-8, 2003, NASA TM-2003-212327, ARL-TR-2958.

${ }^{40}$ Romero, R., Summers, H., and Cronkhite, J., "Feasibility Study of a Rotorcraft Health and Usage Monitoring System (HUMS): Results of Operator's Evaluation,” NASA CR-198446, Feb. 1996. 